Letter

\title{
Residual Stress, Defects and Grain Morphology of Ti-6Al-4V Alloy Produced by Ultrasonic Impact Treatment Assisted Selective Laser Melting
}

\author{
Meixia Zhang ${ }^{1}$, Changmeng Liu ${ }^{1, *}$, Xuezhi Shi ${ }^{1}$, Xianping Chen ${ }^{2}$, Cheng Chen ${ }^{1}$, Jianhua Zuo ${ }^{1}$, \\ Jiping $\mathrm{Lu}^{1}$ and Shuyuan Ma ${ }^{1}$ \\ 1 School of Mechanical Engineering, Beijing Institute of Technology, Beijing 100081, China; \\ mxzhang1@hotmail.com (M.Z.); shixuezhisheo@gmail.com (X.S.); cc.lime@hotmail.com (C.C.); \\ jhzuo@bit.edu.cn (J.Z.); jipinglu@bit.edu.cn (J.L.); bitmc@bit.edu.cn (S.M.) \\ 2 Beijing Institute of Astronautical Systems Engineering, Beijing 100076, China; chenxianping2000@gmail.com \\ * Correspondence: liuchangmeng@bit.edu.cn; Tel.: +86-10-68915097 \\ Academic Editor: Peter Van Puyvelde \\ Received: 4 September 2016; Accepted: 11 October 2016; Published: 25 October 2016
}

\begin{abstract}
For large-scale selective laser melting (SLM) additive manufacturing technology, three main problems severely restrict its development and application, namely the residual stress, defects, and columnar grains with anisotropy. To overcome these problems, a new method is proposed by combining SLM with ultrasonic impact treatment (UIT) technique. This study explores the feasibility of UIT assisted SLM, as well as the effect of UIT on the residual stress, defects and $\beta$ grains of Ti-6Al-4V alloy sample. The results indicate that after the application of UIT during SLM, residual stress can be largely reduced and defects can be hammered flat and even eliminated. Meanwhile, the epitaxial growth of columnar grains is prevented, and fine equiaxed grains are formed due to plastic deformation and recrystallization.
\end{abstract}

Keywords: selective laser melting; ultrasonic impact treatment; residual stress; defects; grain

\section{Introduction}

Selective laser melting (SLM), as an additive manufacturing technology, is mainly used to fabricate small scale and high-precision components [1-4]. However, in recent years, large-scale manufacturing has gradually become an important trend of SLM. Until now, the size of the largest available commercial equipment has achieved $800 \times 400 \times 500 \mathrm{~mm}^{3}$ (Concept Laser $X$ line 2000R). It is highly likely that SLM can be used to fabricate large-scale components in the near future, such as large scale aerospace titanium components. Compared with other large-scale additive manufacturing technologies based on powder or wire feeding [5-7], the predominant advantage of the large-scale SLM lies in the better mechanical properties and higher precision.

However, three problems still severely restrict the development and application of large-scale SLM. The first one is the residual stress [8], which causes the distortion of components, the difficulty of spreading powder and even the termination of SLM process. The second one is defects, including incomplete fusion defects, and pores, etc. These defects largely reduce the fatigue performance of alloys [9]. Currently, the residual defects are generally eliminated by post hot isostatic pressing. However, for large-scale components, this method will be difficult and costly. The third one is columnar grains. Although the grain sizes of the alloys fabricated by SLM are fine, the columnar morphology results in mechanical anisotropy, and hence restricts its application.

In order to solve the above problems, a novel method is proposed by combining SLM with ultrasonic impact treatment (UIT) technique. UIT is one kind of well-known surface plastic deformation methods (see Figure 1a), which was originally developed to relax residual stress and improve the 
fatigue performance of welded structures [10,11]. It is usually used for welded processing to eliminate residual tensile stress, and is also used for the surface treatment of bulk material to implant compressive stress and form fine grain zone. UIT can provide a number of beneficial effects on the surface region of alloys by introducing compressive plastic deformation. According to the different treatment effects, the surface can be divided into three zones, as shown in Figure 1b [12]: (i) zone of grain refinement at the top surface. Its depth is about $10-30 \mu \mathrm{m}$ for titanium alloys $[13,14]$. This zone is caused by severe plastic deformation and recrystallization; (ii) zone of plastic deformation with compressive residual stress, but without recrystallization. This zone has a depth of more than $200 \mu \mathrm{m}$ for titanium alloys [15]; (iii) zone of stress relaxation with a depth of several millimeters [12]. For SLM, the thickness of the deposited layer is about $30-200 \mu \mathrm{m}$. Therefore, it is hopeful that UIT can effectively reduce the residual stresses, and may eliminate the defects and break the columnar grains. In addition, because the UIT impact head is small, it is suitable to be integrated into large-scale equipment of SLM. Based on these considerations, we explore the feasibility of UIT assisted SLM in this study. A preliminary investigation is undertaken to determine the effect of UIT on the residual stress, defects and grains of Ti-6Al-4V titanium alloy samples.

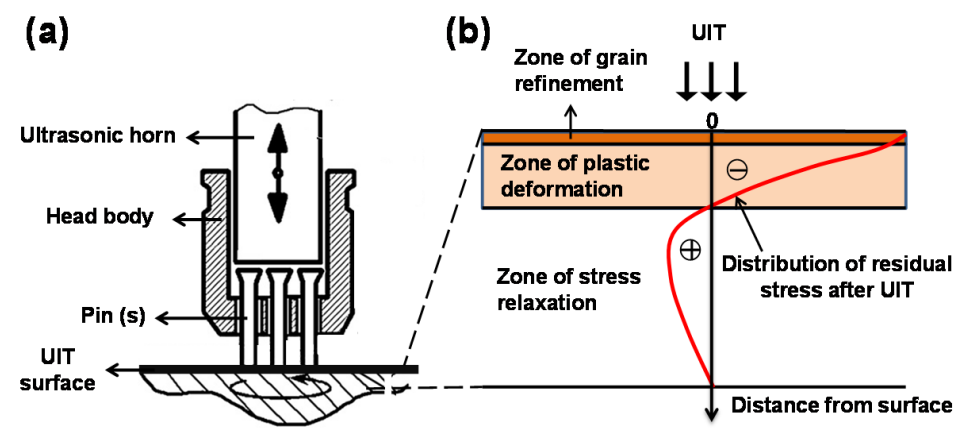

Figure 1. (a) Schematic view of the impact head of ultrasonic impact treatment (UIT); (b) Sectional view of the surface region for the sample treated by UIT.

\section{Materials and Methods}

The UIT impact head was integrated into the self-developed SLM system as schematically shown in Figure 2a. The gas atomized Ti6Al4V powder with a size range of 53-106 $\mu \mathrm{m}$ supplied by AVIC BIAM was used in the experiments. The average particle size of powder is $68 \mu \mathrm{m}(\mathrm{d} 10: 57 \mu \mathrm{m}, \mathrm{d} 90: 95 \mu \mathrm{m})$ and the apparent density of powder is $2.48 \mathrm{~g} / \mathrm{cm}^{3}$. Four Ti-6Al-4V samples about $30 \mathrm{~mm} \times 30 \mathrm{~mm} \times 2 \mathrm{~mm}$ (10 layers) were fabricated, including SLM samples without and with defects, UIT assisted SLM samples without and with defects as shown in Figure 2e.

A fiber laser (YLR-WC, IPG Photonics Corporation, Oxford, MA, USA) with a maximum power of $500 \mathrm{~W}$ in continuous laser mode is used for the equipment. The size of the build envelop is $\Phi 200 \times 100$, platform is at room temperature $\left(25^{\circ} \mathrm{C}\right)$. The working chamber provides a closed environment which is filled with Argon as a protective gas to maintain the content of oxygen below $50 \mathrm{ppm}$. Because the final purpose of this study is to fabricate large-scale components, the SLM process parameters were chosen to ensure high-efficiency. Here, laser power is $400 \mathrm{~W}$, a spot size is approximately $200 \mu \mathrm{m}$, a laser wavelength is $1074 \mathrm{~nm}$, scanning speed is $50 \mathrm{~mm} / \mathrm{s}$, hatch spacing is $0.6 \mathrm{~mm}$, and layer thickness is $200 \mu \mathrm{m}$. The strategy for the fabrication of the cubic specimens is cross-hatching technique. Note that it is difficult to observe the defects in UIT assisted SLM sample, because the density of SLM sample has reached $99.9 \%$. Hence, we compare the SLM sample with defects and UIT assisted SLM sample with defects, in order to study the effect of UIT on the defects. When fabricating SLM sample with defects, the hatch spacing was changed to be $0.8 \mathrm{~mm}$ on purpose. During UIT processing, the dimensions of the UIT head is $\Phi 5 \mathrm{~mm}$, the output frequency is $20 \mathrm{KHz}$ and output power is $0.8 \mathrm{~kW}$. Moreover, the moving velocity of the impact head was about $50 \mathrm{~mm} / \mathrm{min}$, and the SLM samples were treated once by UIT when the surface temperature is lower than $50{ }^{\circ} \mathrm{C}$ after every 2 layers were deposited, 
as shown in Figure 2c. Each impacted layer took about $4 \mathrm{~min}$ and the scanning path of UIT head looks like " $Z$ ", as illustrated in Figure 2d.

Metallographic specimens were prepared by conventional mechanical polishing method. A mixture of $1 \mathrm{~mL} \mathrm{HF}, 6 \mathrm{~mL} \mathrm{HNO}_{3}$ and $100 \mathrm{~mL} \mathrm{H}_{2} \mathrm{O}$ was used as the etching agent. The surface morphology and microstructures of the samples were characterized by optical microscopy (OM) and scanning electron microscopy (SEM). The $\beta$ grain size was measured using the metallographic image analysis software SISC IAS v8.0. The quantitative measurement was conducted on at least five OM micrographs with a magnification of 200 for each specimen. The residual stress at the top surface was measured by using the hole-drilling method of ASTM standard E837. The diameter of the hole is $1.5 \mathrm{~mm}$ and the depth is $2 \mathrm{~mm}$, the residual stress is calculated according to the measured release of the strain during the drilling process.

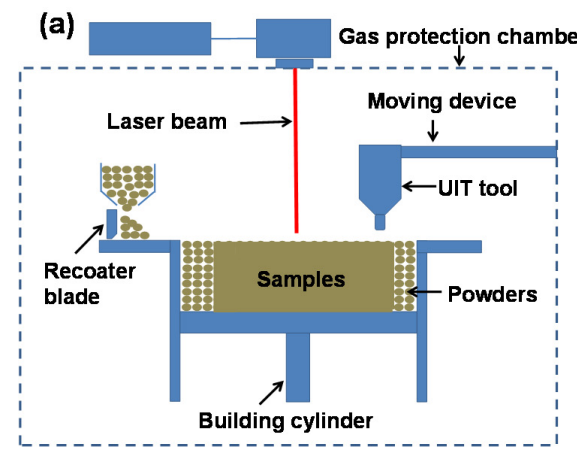

(b)

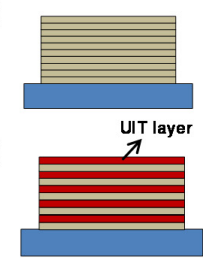

(d)

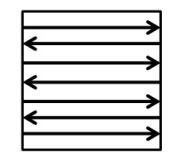

(e)

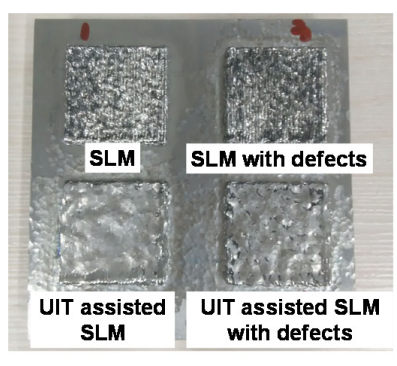

Figure 2. Schematic view of (a) UIT assisted selective laser melting (SLM); (b) SLM sample and (c) UIT assisted SLM sample; (d) scanning path of UIT; (e) four samples in this study.

\section{Results and Discussion}

The top surface morphologies of SLM sample and UIT assisted SLM sample are presented in Figure 3. Figure 3a shows the multi-track morphology on the surface of the SLM sample. There are a lot of spattering powder particles on the surface. Comparatively, the surface of UIT assisted SLM sample is more smooth. It is hard to observe beads and spatter as shown in Figure 3b. Obviously, the compressive plastic deformation produced by UIT optimizes the surface morphology, and the smooth surface is helpful to reduce the defects.
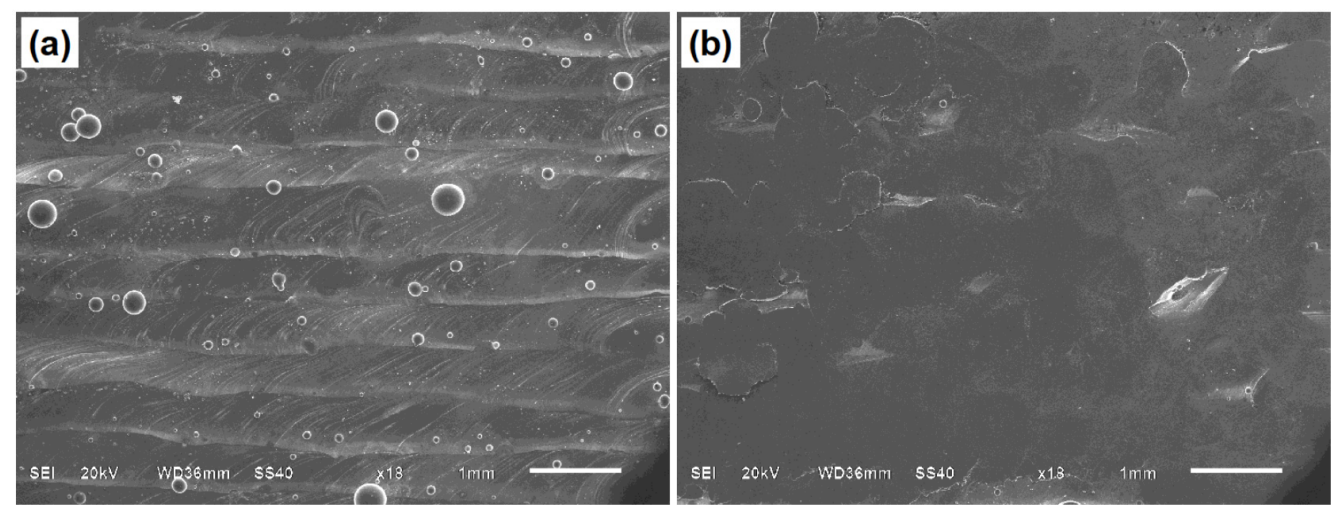

Figure 3. Scanning electron microscopy (SEM) images showing the typical surface morphology of (a) SLM sample; (b) UIT assisted SLM sample.

The average residual stresses of the SLM sample and UIT assisted SLM sample without defects are $176.3 \mathrm{MPa}$ and $49.9 \mathrm{MPa}$, respectively. This clearly shows that the UIT assisted SLM process has a significant advantage of reducing residual stress, and the residual stress value can be largely reduced. 
The reasons can be simply explained as follows. The rapid solidification and high temperature gradient lead to the generation of residual stresses in SLM fabricated sample. According to the solidification shrinkage and temperature gradient mechanism [8], tensile residual stresses exist in new deposited layers. UIT can introduce the compressive stress into the layer, and hence reduce the tensile stress.

Figure 4a shows that there are many large and irregular incomplete fusion defects in the SLM sample, due to the inappropriate hatch spacing [16] (used on purpose to generate defects). However, since UIT is applied after depositing every two layers, some small defects are basically eliminated. Meanwhile, large defects are hammered flat, showing a trend of closure, as shown in Figure 4b. We can clearly see from this comparison that UIT plays a significant role in reducing defects. This is due to the compressive surface plastic deformation caused by UIT. It should be noted that, during the long time SLM additive manufacturing of large-scale components, defects (pores, etc.) are unavoidable. These defects largely reduce the fatigue performance of alloys [9]. However, our above results suggest that UIT assisted SLM may be used to obtain the full density components. Therefore, the costly post hot isostatic pressing method can be avoided.

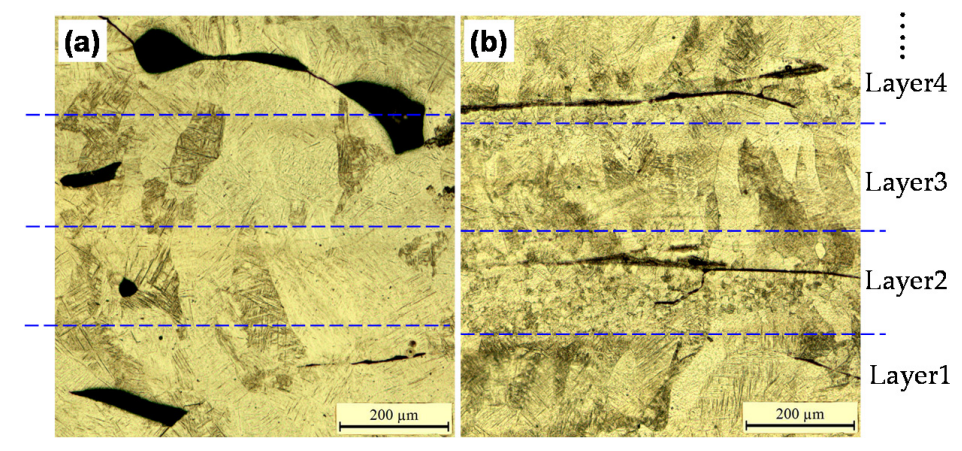

Figure 4. Optical microscopy (OM) images showing the typical macrostructure of (a) of SLM sample with defects and (b) UIT assisted SLM sample with defects, the hatch spacing of two samples is $0.8 \mathrm{~mm}$.

For the SLM sample, long columnar $\beta$ grains dominate in the sample with the average width about $100 \mu \mathrm{m}$ as shown in Figure 5a,b. For the UIT assisted SLM sample, it consists of fine equiaxed grains with the diameter about $20 \mu \mathrm{m}$, and short columnar grains with the width about $50 \mu \mathrm{m}$ and height about $250 \mu \mathrm{m}$ as shown in Figure $5 \mathrm{c}, \mathrm{d}$. Meanwhile, it is interesting to find that the columnar grains and equiaxed grains are distributed alternately, forming a novel bamboo-like morphology (see Figure 5d). Besides, the height of these bamboo-like grains is about $400 \mu \mathrm{m}$, which is identical to the thickness of 2 layers. Considering that the sample was treated once by UIT every 2 layers, this morphology implies that the formation of fine equiaxed grains is associated with UIT.

Next, the grain evolution during UIT assisted SLM is proposed as shown in Figure 6. Firstly, during SLM process, there is high temperature gradient due to rapid heat loss through the substrate or previously deposited layers. This results in the epitaxial growth of $\beta$ grains as schematically shown in Figure 6a [5,17], and hence leads to the long columnar grain morphology in SLM samples (see Figure 5a). During UIT assisted SLM process, when layer 1 and 2 (counting from the bottom layer) are deposited, the columnar grains are also formed. Then, the UIT is applied. Compressive plastic deformation occurs in the surface region as schematically shown in Figure 6b. There are two possible mechanisms for the formation of fine equiaxed grains. One is dynamic recrystallization, which occurs during heavily plastic deformation. The other is reheating and recrystallization. In this case, the sample may also be subjected to some extent of deformation, but the deformation extent is not high enough to directly induce recrystallization. Here, dynamic recrystallization is thought to be not the key mechanism due to the following two clues. Firstly, according to previous research, the depth of dynamic recrystallization zone (i.e., zone of grain refinement in Figure $1 \mathrm{~b}$ ) is generally only about $10-30 \mu \mathrm{m}[13,14]$, which is too thin to be observed. Meanwhile, it can be completely remelted during the depositing of next layer. Furthermore, the depth of the equiaxed grain regions observed in Figure $5 \mathrm{~d}$ 
is significantly larger than this value. Secondly, dynamic recrystallization can results in very fine grain size (about $20-100 \mathrm{~nm}$ ) [13,14]. However, the averaged equiaxed grain size is about $20 \mu \mathrm{m}$. Accordingly, it can be inferred that the fine equiaxed grains generate in the plastic deformation zone, because the compressive plastic deformation can induce high dislocation density and internal energy storage in this zone. During the depositing of Layer 3 (see Figure 6d), the rapid heating will lead to the recrystallization in the heat treated zone under the melting pool. Therefore, the fine equiaxed grains gradually form, and the grain morphology turns to be bamboo-like.
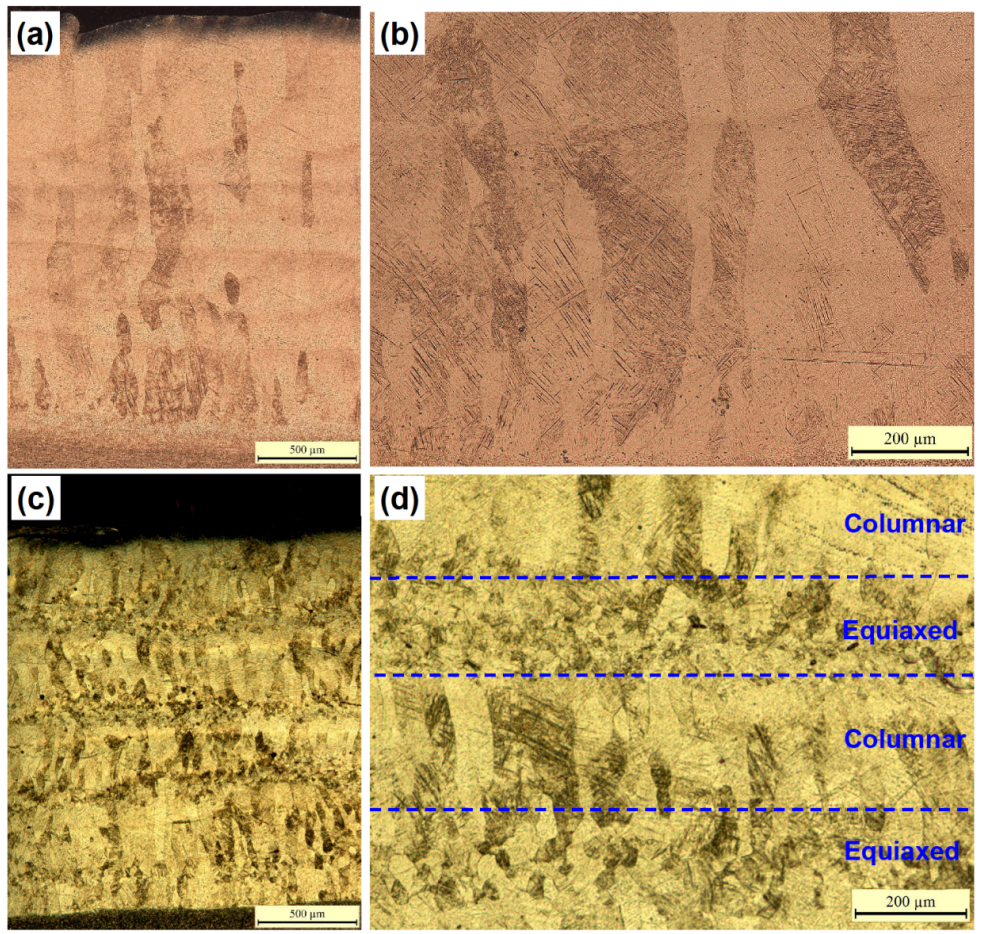

Figure 5. OM images showing the typical $(\mathbf{a}, \mathbf{b})$ macrostructure and grain morphology of SLM sample; $(\mathbf{c}, \mathbf{d})$ macrostructure and grain morphology of UIT assisted SLM sample, all samples' hatch spacing is $0.6 \mathrm{~mm}$.

(a)

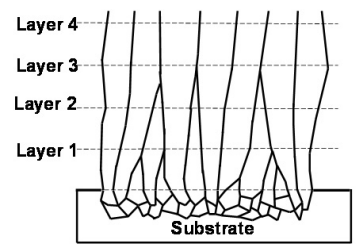

(c)

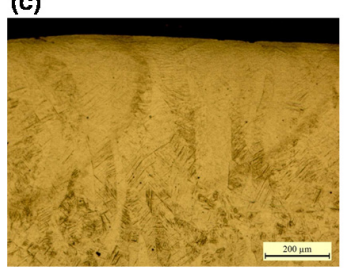

(b)
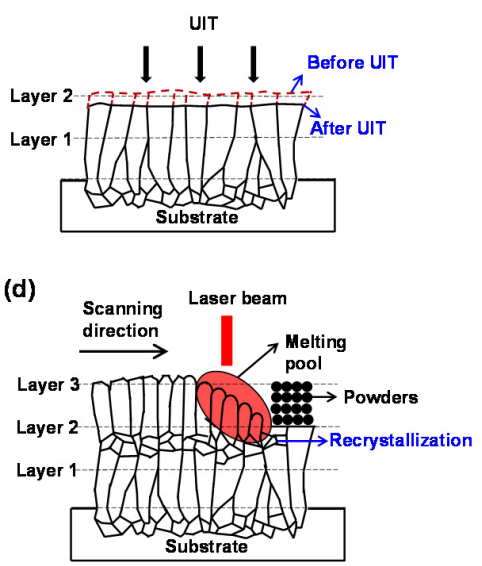

Figure 6. (a) Schematic view of epitaxial growth of columnar grains during SLM; (b) Schematic view of compressive plastic deformation introduced by UIT; (c) OM image showing the grain morphology in the last layer of UIT assisted SLM sample with $0.6 \mathrm{~mm}$ hatch spacing, which has been treated by UIT; (d) Schematic view of the formation of equiaxed grains due to recrystallization during laser melting. 


\section{Conclusions}

In this study, UIT is applied to assist SLM, which successfully reduces the residual stress and defects, and obtains fine equiaxed grains. The residual stress is largely reduced, and defects are reduced and even eliminated by plastic deformation. In addition, UIT can eliminate the long columnar grains in SLM samples. Fine equiaxed grains are formed in the treated layers. This is on the one hand due to the plastic deformation caused by UIT, and on the other hand due to the recrystallization assisted by rapid heating during SLM. These findings demonstrate the effectiveness of UIT assisted SLM for the fabrication of high performance titanium alloy with low residual stress. It opens a new direction in the production of large-scale titanium alloy components by SLM.

Acknowledgments: The work was financially supported by the National Natural Science Foundation of China (51505033), Beijing Natural Science Foundation (3162027), and Excellent Young Scholars Research Fund of Beijing Institute of Technology (2015YG0302).

Author Contributions: Meixia Zhang performed most of experiments and wrote this manuscript. Changmeng Liu designed the research, analyzed the experimental data and gave some constructive suggestions. Xuezhi Shi and Cheng Chen helped to do some experiments. Xianping Chen, Jianhua Zuo, Jiping Lu and Shuyuan Ma participated in the discussion of the results and guided the writing of the article. The authors are grateful to Yinan Cui at University of California, Los Angeles for helpful discussions.

Conflicts of Interest: The authors declare no conflict of interest.

\section{References}

1. Bremen, S.; Meiners, W.; Diatlov, A. Selective Laser Melting. Laser Tech. J. 2012, 9, 33-38. [CrossRef]

2. Davidson, K.; Singamneni, S. Selective Laser Melting of Duplex Stainless Steel Powders: An Investigation. Mater. Manuf. Process. 2016, 31, 1543-1555. [CrossRef]

3. Hu, D.; Wang, Y.; Zhang, D.; Hao, L.; Jiang, J.; Li, Z.; Chen, Y. Experimental Investigation on Selective Laser Melting of Bulk Net-Shape Pure Magnesium. Mater. Manuf. Process. 2015, 30, 1298-1304. [CrossRef]

4. Zhang, D.; Cai, Q.; Liu, J. Formation of nanocrystalline tungsten by selective laser melting of tungsten powder. Mater. Manuf. Process. 2012, 27, 1267-1270. [CrossRef]

5. Frazier, W.E. Metal Additive Manufacturing: A Review. J. Mater. Eng. Perform. 2014, 23, $1917-1928$. [CrossRef]

6. Liu, C.; Lu, Y.; Tian, X.; Liu, D. Influence of continuous grain boundary $\alpha$ on ductility of laser melting deposited titanium alloys. Mater. Sci. Eng. A 2016, 661, 145-151. [CrossRef]

7. Liu, C.; Yu, L.; Zhang, A.; Tian, X.; Liu, D.; Ma, S. Beta heat treatment of laser melting deposited high strength near $\beta$ titanium alloy. Mater. Sci. Eng. A 2016, 673, 185-192. [CrossRef]

8. Mercelis, P.; Kruth, J.-P. Residual stresses in selective laser sintering and selective laser melting. Rapid Prototyp. J. 2006, 12, 254-265. [CrossRef]

9. Leuders, S.; Thöne, M.; Riemer, A.; Niendorf, T.; Tröster, T.; Richard, H.A.; Maier, H.J. On the mechanical behaviour of titanium alloy TiAl6V4 manufactured by selective laser melting: Fatigue resistance and crack growth performance. Int. J. Fatigue 2013, 48, 300-307. [CrossRef]

10. Gao, H.; Dutta, R.K.; Huizenga, R.M.; Amirthalingam, M.; Hermans, M.J.M.; Buslaps, T.; Richardson, I.M. Stress relaxation due to ultrasonic impact treatment on multi-pass welds. Sci. Technol. Weld. Join. 2014, 19, 505-513. [CrossRef]

11. Mordyuk, B.N.; Prokopenko, G.I.; Milman, Y.V.; Iefimov, M.O.; Sameljuk, A.V. Enhanced fatigue durability of Al-6Mg alloy by applying ultrasonic impact peening: Effects of surface hardening and reinforcement with AlCuFe quasicrystalline particles. Mater. Sci. Eng. A 2013, 563, 138-146. [CrossRef]

12. Zhao, X.; Wang, M.; Zhang, Z.; Liu, Y. The effect of ultrasonic peening treatment on fatigue performance of welded joints. Materials 2016, 9, 471. [CrossRef]

13. Mordyuk, B.N.; Prokopenko, G.I. Ultrasonic impact peening for the surface properties' management. J. Sound Vib. 2007, 308, 855-866. [CrossRef]

14. Mordyuk, B.N.; Prokopenko, G.I. Fatigue life improvement of $\alpha$-titanium by novel ultrasonically assisted technique. Mater. Sci. Eng. A 2006, 437, 396-405. [CrossRef] 
15. Amanov, A.; Cho, I.-S.; Kim, D.-E.; Pyun, Y.-S. Fretting wear and friction reduction of CP titanium and Ti-6Al-4V alloy by ultrasonic nanocrystalline surface modification. Surf. Coat. Technol. 2012, 207, 135-142. [CrossRef]

16. Wits, W.W.; Carmignato, S.; Zanini, F.; Vaneker, T.H.J. Porosity testing methods for the quality assessment of selective laser melted parts. CIRP Ann. Manuf. Technol. 2016, 65, 201-204. [CrossRef]

17. Ravi, G.A.; Qiu, C.; Attallah, M.M. Microstructural control in a Ti-based alloy by changing laser processing mode and power during direct laser deposition. Mater. Lett. 2016, 179, 104-108. [CrossRef]

(C) 2016 by the authors; licensee MDPI, Basel, Switzerland. This article is an open access article distributed under the terms and conditions of the Creative Commons Attribution (CC-BY) license (http://creativecommons.org/licenses/by/4.0/). 